\title{
The Role of Families in
}

\section{Young Children's Mental Health}

\author{
Lala Rubiyah \\ Universitas Pendidikan Indonesia \\ Bandung, West Java,Indonesia \\ lalarubiyah@student.upi.edu
}

\begin{abstract}
The major goal is to provide the understanding on how important the role of family in young children's mental health.The condition of family plays an important role in children's development, especially on their mental health development. Based on previous studies, mental health in early childhood is in consequence of several factors, starting from genes, to the parenting method applied by the family and environment. The problem that arise in this modern life is that there are numbers of mothers be at work, so that they are lack in caring and nurturing their children. The educational role of mothers, as well as nurturing, and caring to their children was take effect on child's mental health from early childhood. There were several factors that underlying their decision to be at work. Among others are economic factors (living in poverty), as well as solely to career. Thereupon the deficiency on nurturing occur as the result, their children being neglected and exhibit the seekingfor-attention-behavioral-pattern; not even rule out the possibility of maladaptive behavior. There was a sense of anxiety, difficulty in learning, and a hyperactive behavior as the psychological impact of mental health disorders in children. The countermeasures for mental health disorders in children was starting within the family. The role of a good family will also foster children's good mental health from early childhood.
\end{abstract}

Keywords--family; mental health; early childhood

\section{INTRODUCTION}

Mental health problems need to be evaluated, because the mental health of children from the early life to adulthood will determine their success. It can also be seen in the pattern of parenting in the family, the role of the mother and the father [1], [2] in providing care for children, from infancy until they stepped on adulthood. The problem is that today, many mothers are working so for child care cannot be given well. The mental health of children will be vulnerable if they grow in an environment where they are subjected to violence, neglection, and poverty [3].

Accordingly, it is clear that the role of the family is very important in growing mental health in children from the earliest age. This article is compiled to discussing the role of the family in establishing a good mental health in children from an early age.

\section{DISCUSSION}

Causative Factors of Mental Health Disorders

Mental health is a term that refers to the emotional state, the psychological state, and social well-being of the individual [4]. One's emotional state could be disrupted, this is very dangerous for their mental health. The causes of mental health disorders in children include internal factors and external factors

\section{Internal Factors}

Which begins since they are in the mother's womb. According to previous research, that gene or innate factors will give a profound influence on mental health disorders in children. Many researchers suspect that food intake (nutrition) is also a factor in mental health problems in children[5], [6]. Good nutrition is substantial for the physical and mental development of children[1]. It is important to note that good nutritional intake is prominent, deficiencies in certain nutrients, such as iodine, may cause mental developmental delays or cognitive impairment[1], [5]. The brain is particularly susceptible to the adverse effects of malnutrition from pregnancy to the first 2-3 years of life; malnutrition will cause greater damage[3], [7].

The maternal genetic factors in children have a serious impact; a depressed mother, who is suffering from anxiety, and getting psychological pressure during pregnancy will give birth to an anxious, crying, sleeplessness, depressed, post traumatic disorder, autism and mental health disorder as well. Many studies have proven that the attachment between mother and child is very strong, so anything felt by a mother will have an impact on fetal development in the mother's womb. Pressure and violence experienced by pregnant women can cause physical harm to the baby she is born, such as premature birth, stunted growth and development, and high-risk neurological development.

\section{External Factors}

The family is the primary surrounding where children are growing and developing both physically and psychologically. The lack of parental involvement in parenting[6], [8], will be 
bad for the child. Such conditions do not occur only in lowincome societies, but even in well-established families. The phenomenon of today is there are more working mothers[2], [9], this will result in the attachment loosening between mothers and children. Family conflicts [10] can also be a contributing factor to mental health disorders in children.

Children that grow up in the risky families, especially those in a poor and violent environment, tend to exhibit behaviors that threaten their own health, including smoking, alcohol abuse, drug abuse, chronic stress[11], [12], and this is immensely terrible for children's mental health.

Other contributing factors are disharmoniousfamily and parental divorce. Families who experience parental divorce will inflict depression in children they will become unearthly quiet, and fall on difficulty to socialize. Parental quarrels and authoritarian parental attitudes tend to shoving children in mental disorders, in which their mental state do not develop positively. Children become insecure, feel unappreciated, and lack of confident.

\section{The Impact of Mental Health Disorders Toward in Children}

Mental health, including emotional and behavioral, impacts on people's life, including personal relationships and physical health[10]. Children not only suffer from behavioral difficulties, but may also experience academic failure[4], [13], the increasing of the prevalence of mental health problems and difficulties among children and adolescents putting a large burden both financially and emotionally to the individuals and their families[14], [15].

The impact of mental health problems on infants and toddlers may be reflected in physical symptoms, such as decreasing weight, slow growth and development, crying, sleep problems, aggressive behavior, and fear

\section{The Role of Family in Overcoming the Young Children's Mental Health}

The family and the surroundings have an important role in the process of forming the mental health of children. The involvement of parents and the surrounding in childcare is part of social norms [6], [8]for children who get care from a harmonious family will have stable levels of growth and development. The recent study proved that the imbalance of the role of father and mother can lead to poor parenting.

Family involvement is an aspect of service throughout the ages, family involvement has been typically defined in the research as the impetus and maintenance of time-consuming services[8], [16]. Family education, building family involvement in decision making, and keeping families informed in the complex treatment process consists of several processes, including family empowerment, and family support of the mental health of children[5]. In addition, a study positively proven that family involvement can separate rigid patterns in mental health care in children[5].
Parents should also play a role in providing good nutrition, since nutrients are important for the physical and mental development of children [2]. Children who are deficient in certain nutrients, such as iodine, may cause mental delay or cognitive impairment [10]. The brain is particularly susceptible to the adverse effects of malnutrition from pregnancy to the first 2-3 years of life; again, malnutrition means greater damage [5]. A safe, comfortable, and supportive environment for child growth will have a good impact on the child's mental health.

The support provided by family support for children - such as giving attention, motivating children in learning, promoting positive attitudes, constructing the harmonious atmosphere, preserving the integrity in family, and laid the basics of religious values implanted from early childhood - can reduce the occurrence of mental health disorders in children.

A roles share-out between father(s) and mother(s) who are busy working, will assure that children receiving the attention and affection they needed. A democratic attitude, whichaway from violence, will foster self-confidence in children, hence they will be able to interact with their peers favorably.

\section{CONCLUSION}

Child mental health has been built since the child in the mother's womb, it must be created a stable and healthy mother's condition during pregnancy. Families should be actively involved in the development of children's mental health, this will greatly support the growth and development of children until they grow up.. Care that provided by mothers and fathers with a balanced attention can avoid children from mental health disorder symptoms from an early age. School and community environments that are away from violence, poverty, and bad press can reduce mental health disorders in children, so children can feel comfort and security in community life. A healthy child can learn well and grow in accordance with the stage of development optimally.

\section{References}

[1] B. L. Green, M. Everhart, L. Gordon, and M. Garcia Gettman, "Characteristics of effective mental health consultation in early childhood settings: Multilevel analysis of a national survey," Top. Early Child. Spec. Educ., vol. 26, no. 3, pp. 142-152, 2006.

[2] M. A. Milkie and C. H. Warner, "Classroom learning environments and the mental health of first grade children," J. Health Soc. Behav., vol. 52, no. 1, pp. 4-22, 2011.

[3] L. Newman and P. Birleson, "Mental health planning for children and youth: is it developmentally appropriate?," Australas. Psychiatry, vol. 20, no. 2, pp. 91-97, 2012.

[4] N. S. C. on the D. Child, Establishing a Level Foundation for Life: Mental Health Begins in Early Childhood. Harvard University, Center on the Developing Child, 2012.

[5] D. A. Chambers, H. Ringeisen, and E. E. Hickman, "Federal, state, and foundation initiatives around evidence-based practices for child and adolescent mental health," Child Adolesc. Psychiatr. Clin. N. Am., vol. 14, no. 2, pp. 307-327, 2005.

[6] S. R. Zubrick, S. R. Silburn, P. Burton, and E. Blair, "Mental health disorders in children and young people: scope, cause and prevention," Aust. N. Z. J. Psychiatry, vol. 34, no. 4, pp. 570-578, 2000. 
[7] M. Hoeve, O. F. Colins, E. A. Mulder, R. Loeber, G. J. J. Stams, and R. R. Vermeiren, "Trauma and mental health problems in adolescent males: Differences between childhood-onset and adolescent-onset offenders," Crim. Justice Behav., vol. 42, no. 7, pp. 685-702, 2015

[8] J. T. McCracken et al., "Risperidone in children with autism and serious behavioral problems," N. Engl. J. Med., vol. 347, no. 5, pp. 314-321, 2002.

[9] C. Low and S. Shepard, "Early childhood mental health consultation in early care environments: An introduction," Brown Univ. Child Adolesc. Behav. Lett., vol. 26, no. 3, pp. 1-6, 2010.

[10] M. S. Scheeringa, C. H. Zeanah, M. J. Drell, and J. A. Larrieu, "Two approaches to the diagnosis of posttraumatic stress disorder in infancy and early childhood," J. Am. Acad. Child Adolesc. Psychiatry, vol. 34, no. 2, pp. 191-200, 1995.

[11] A. F. Jorm, "Mental health literacy: empowering the community to take action for better mental health.," Am. Psychol., vol. 67, no. 3, p. 231, 2012.

[12] M. Vänskä et al., "Maternal pre-and postnatal mental health trajectories and child mental health and development: Prospective study in a normative and formerly infertile sample," Int. J. Behav. Dev., vol. 35, no. 6, pp. 517-531, 2011.

[13] C. B. Asanbe, C. Hall, and C. Bolden, "Mental health disorders in children of non-drug-abusing parents: A sample from a rural community devastated by methamphetamine," J. Child Health Care, vol. 16, no. 1, pp. 15-25, 2012.

[14] P. Wang et al., "Identifying functional connectomics abnormality in attention deficit hyperactivity disorder," in Biomedical Imaging (ISBI), 2013 IEEE 10th International Symposium on, 2013, pp. 544-547.

[15] J. E. Banta, R. N. Khoie-Mayer, C. K. Somaiya, O. McKinney, and G. Segovia-Siapco, "Mental health and food consumption among California children 5-11 years of age," Nutr. Health, vol. 22, no. 3-4, pp. 237-253, 2013 .

[16] L. S. Mayberry and C. A. Heflinger, "The role of quality service systems in involving families in mental health treatment for children with severe emotional disturbances," J. Emot. Behav. Disord., vol. 20, no. 4 , pp. 260-274, 2012. 